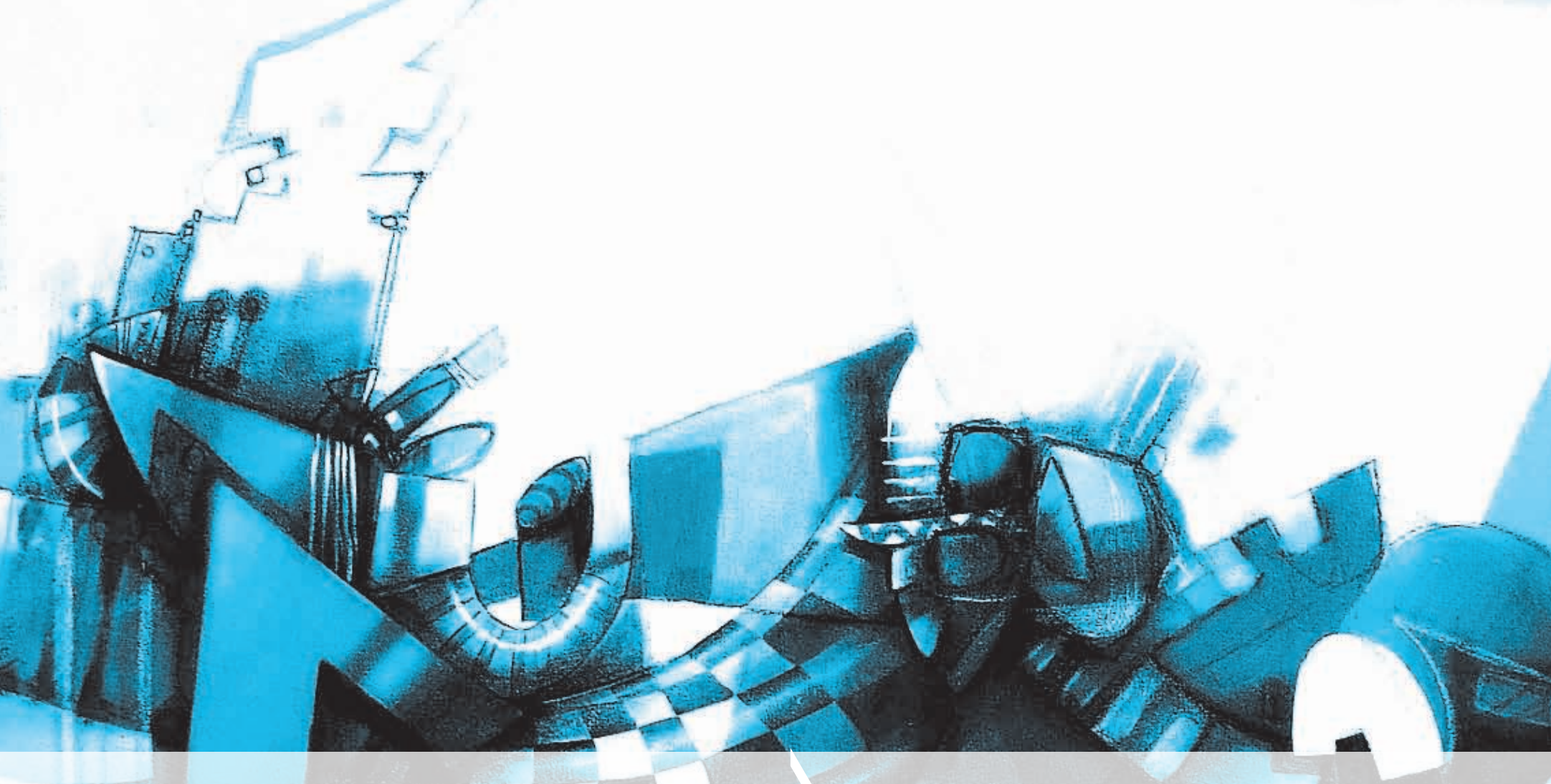

\title{
Jubilaciones del indigenismo en las itinerancias de maestros y maestras indígenas ch'oles del municipio de tila, chiapas
}

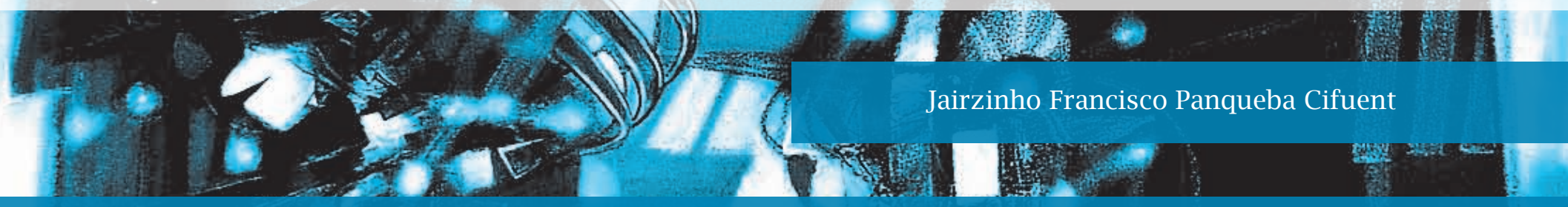

* Este artículo es una versión adaptada de mi disertación doctoral presentada en la ciudad de Guadalajara, Jalisco (Mexico) el 14 de diciembre de 2010. La investigación se tituló: "Jubilaciones del indigenismo y mercado de etnicidades en el municipio de Tila, Chiapas: sus manifestaciones en las itinerancias territoriales del magisterio ch'ol". Para su ejecución recibí una beca del gobierno mexicano a través de la Secretaría de Relaciones Exteriores y el ICETEX (Colombia), una comisión de estudios por parte de la Secretaría de Educación Distrital de Bogotá y una beca-tesis por parte del Centro de Investigaciones y Estudios Superiores en Antropología CIESAS- México. 


\section{Resumen}

El artículo presenta los contextos de vida de tres generaciones magisteriales del sistema de educación primaria indígena del territorio ch'ol del municipio de Tila, norte del estado de Chiapas, México. En ellos se analizan las continuidades y las transformaciones que en y desde las políticas indigenistas se han venido gestando en territorio ch'ol, con relación a la dimensión económica de la etnicidad. Por ello acude a un repaso de la génesis de las políticas indigenistas y de su aplicación en el ámbito educativo. Y de acuerdo a ello, revisar las maneras como la población ch'ol va conformando sus identidades desde una dimensión económica. Esto es, las formas de negociar los procesos de las etnicidades tanto en los espacios creados por las políticas indigenistas, como en los espacios que poco a poco se van abriendo las propias personas y comunidades.

\section{Palabras Clave}

Chiapas, indigenismo, itinerancias, educación, territorios, identidades

\section{Resumo}

O artigo apresenta os contextos de vida de três gerações magistrais do sistema de ensino primário indígena do território ch'ol, municipalidade de Tila, norte do estado de Chiapas, México. Neles são analisadas as continuidades e as transformações que em e dos políticos indigenistas veio a pessoa, enquanto criando em território de ch'ol, com relação para a dimensão econômica do etnicidade. Esta é uma revisão da gênese das políticas indigenistas e a aplicação deles/delas no ambiente educacional. De acordo com isto, revisar os modos como a população de ch'ol vai conformar as identidades deles/delas de uma dimensão econômica. Isto é, as formas de negociar os processos dos etnicidade nos espaços criadas pelos políticos indigenistas, e nos espaços que pouco a pouco vão abrir próprias pessoas e comunidades.

\section{Palavras chave}

Chiapas, indigenismo, itinerancias, territórios, educação, identidades

\section{Summary:}

The article presents the life's contexts of three magisterial generations of the indigenous primary education system of the ch'ol territory, municipality of Tila, north of the state of Chiapas, Mexico. In them the continuities and the transformations are analyzed that in and from the indigenist politicians one has come gestating in ch'ol territory, with relationship to the economic dimension of the ethnicity. This is a review of the genesis of the indigenist politics and their application in the educational environment. According to it, to revise the ways like the ch'ol population goes conforming their identities from an economic dimension. This is, the forms of negotiating the processes of the ethnicities in the spaces created by the indigenist politicians, and in the spaces that little by little go opening up own people and communities.

\section{Keywords}

Chiapas, indigenism, itinerancies, territories, education, identities

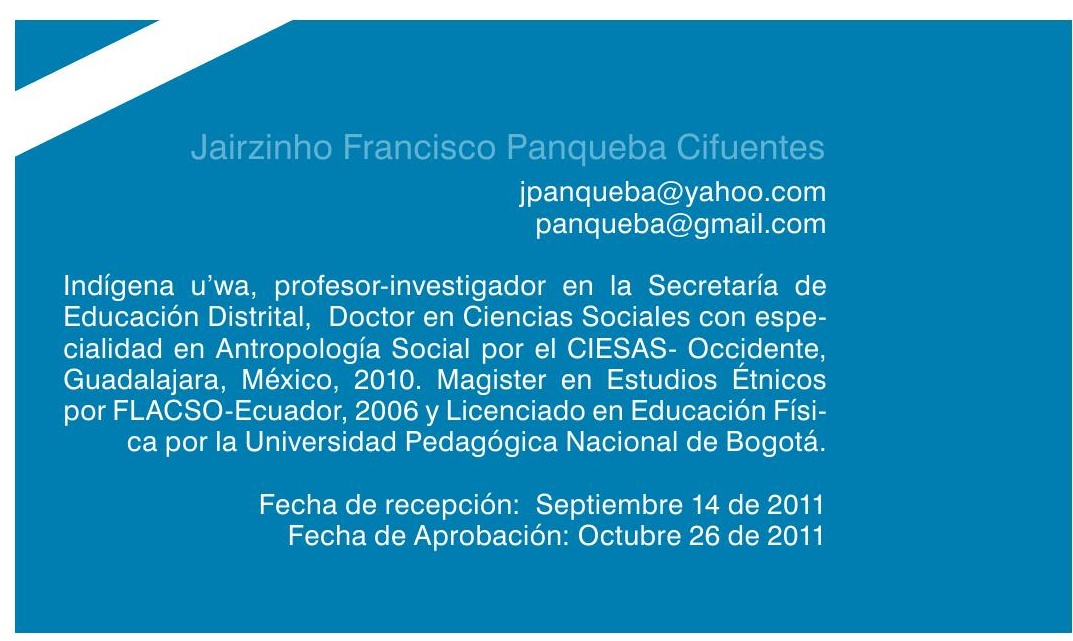




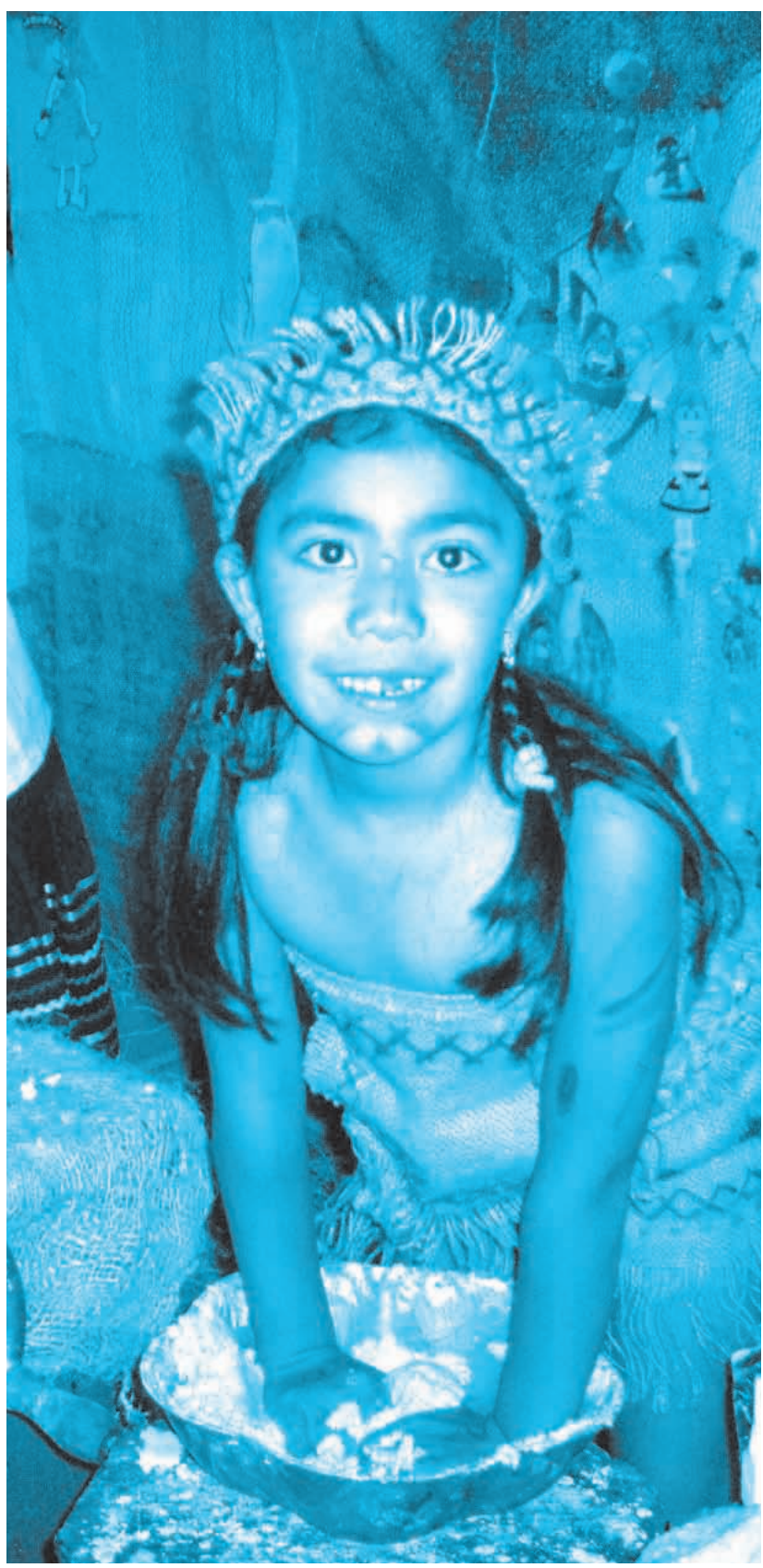

\section{Introducción}

Una de las formas que las autoridades del Estado de Chiapas (México), empleó para relajar los efectos del levantamiento neo-zapatista del año 1994, fue la ejecución del Proyecto Educador Comunitario Indígena -PECI-. Este consistió en convocar jóvenes indígenas para que enseñaran en sus propias comunidades que no contaban con atención educativa. En su mayoría, los y las jóvenes pertenecen a las étnias tzeltal, tzotzil, ch'ol, tojolabal, mam y lacandón, todos pertenecientes al tronco lingüístico maya. Su labor sería recompensada con una beca de estudios para culminar la secundaria, el bachillerato y en muy limitados casos, la formación universitaria. Al día de hoy, por una ínfima suma de dinero mensual, los y las jóvenes del PECl se aventuran por diferentes escuelas y comunidades para prestar el servicio educativo. La "beca", que oscila entre los 853 y los 1837 pesos mexicanos mensuales (unos 80 a 150 dólares estadounidenses), se ofrece para adelantar estudios de bachillerato, preparatoria o universidad. Fue así como desde mediados de la década de 1990, el PECl entró a hacer parte del repertorio educativo para la población indígena chiapaneca. EI PECI se incorporó a programas como CONAFE (Consejo Nacional de Fomento Educativo), que también es una beca para adelantar formación profesional, a cambio de impartir clases en el nivel preescolar de escuelas rurales y de territorios indígenas.

Esta forma de vinculación magisterial indígena no fue un invento nuevo. Tuvo precedente durante la década de 1950, cuando el Instituto Nacional Indigenista (INI) venía formando agentes educativos para la castellanización, la modernización e integración de las poblaciones indígenas a la nación mexicana. El trabajo lo aplicaron como experiencia piloto en la región de los altos de Chiapas, hasta donde llegaron en su mayoría, indígenas tzotziles y tzeltales. También se incorporaron tojolabales y ch'oles en menor medida. Su vínculo era en calidad de "promotores interculturales bilingües". Con el paso de los años, sus esfuerzos personales en cursos de profesionalización, y la movilización colectiva, hicieron posible el cambio de estatus, hasta lograr la vinculación como profesores bilingües. 
Un hecho similar de vinculación docente vivieron jóvenes procedentes de Tila, Sabanilla, Salto de Agua y Tumbalá, municipios del norte chiapaneco, durante la década de 1970. Para aquel tiempo, el INI y la Secretaría de Educación Pública (SEP), a través de la Dirección General de Educación Indígena (DGEI), resolvieron expandir la acción indigenista hacia territorio ch'ol. Allí venían siendo atendidas algunas comunidades a través del "maestro rural" en su figura de "gratificado". Es decir, por personas que de manera voluntaria ofrecían instruir a las niñas y a los niños, a cambio de un pequeño salario que se recolectaba entre la comunidad. De igual manera por maestros recién egresados de la escuela normal de San Cristóbal de las Casas.

La vinculación de promotores, becarios y castellanizadores indígenas ha sido una de las acciones del Indigenismo como política de estado (Favre, 1998). Ello en busca de la integración de los pueblos indígenas a la nación, así como de su asimilación del progreso y el desarrollo (económico). Y como afirma el Instituto Interamericano de Derechos Humanos con relación a la ideología y política indigenista: "sacrificando su identidad étnica-cultural" (IIDH, 2000: 40).

Hoy, gracias a las investigaciones sobre la intermediación del promotor intercultural, el maestro bilingüe y el castellanizador, conocemos detalles sobre los poderes locales y las formas de organización regional (Vargas, 1994; Saldivar, 1998; Pérez Vásquez, 2007). Pero ha sido menos clara la forma en que estas personas han transformando las políticas y las etnicidades. O más bien, contamos con mayores referencias sobre el acatamiento del discurso indigenista, dentro de la estructura analítica tradición-modernidad. Pero, ¿cuáles son las propuestas ante la ideología indigenista por parte de los Pueblos Indígenas? Para el tratamiento de la pregunta es importante anticipar que la resolución/reproducción de esta contradicción, tiene lugar en las formas en que los maestros y las maestras se relacionan con las dimensiones-dinámicas de la región.

Para el análisis de la pregunta formulada organicé el presente artículo de la siguiente manera. En primer lugar presento brevemente el indigenismo. De igual manera intento responder cuál ha sido una de las propuestas desde la vida cotidiana de los pueblos indígenas para darle utilidad, para hacer frente y/o para transformar las políticas indigenistas. Es decir aquello a lo que he identificado como las itinerancias territoriales. Seguidamente describo cuál fue el proceso para realizar este trabajo entre la población ch'ol del municipio de Tila. Luego presento algunas de las jubilaciones del indigenismo proclamadas en el título del trabajo, y finalmente unas conclusiones de la investigación.

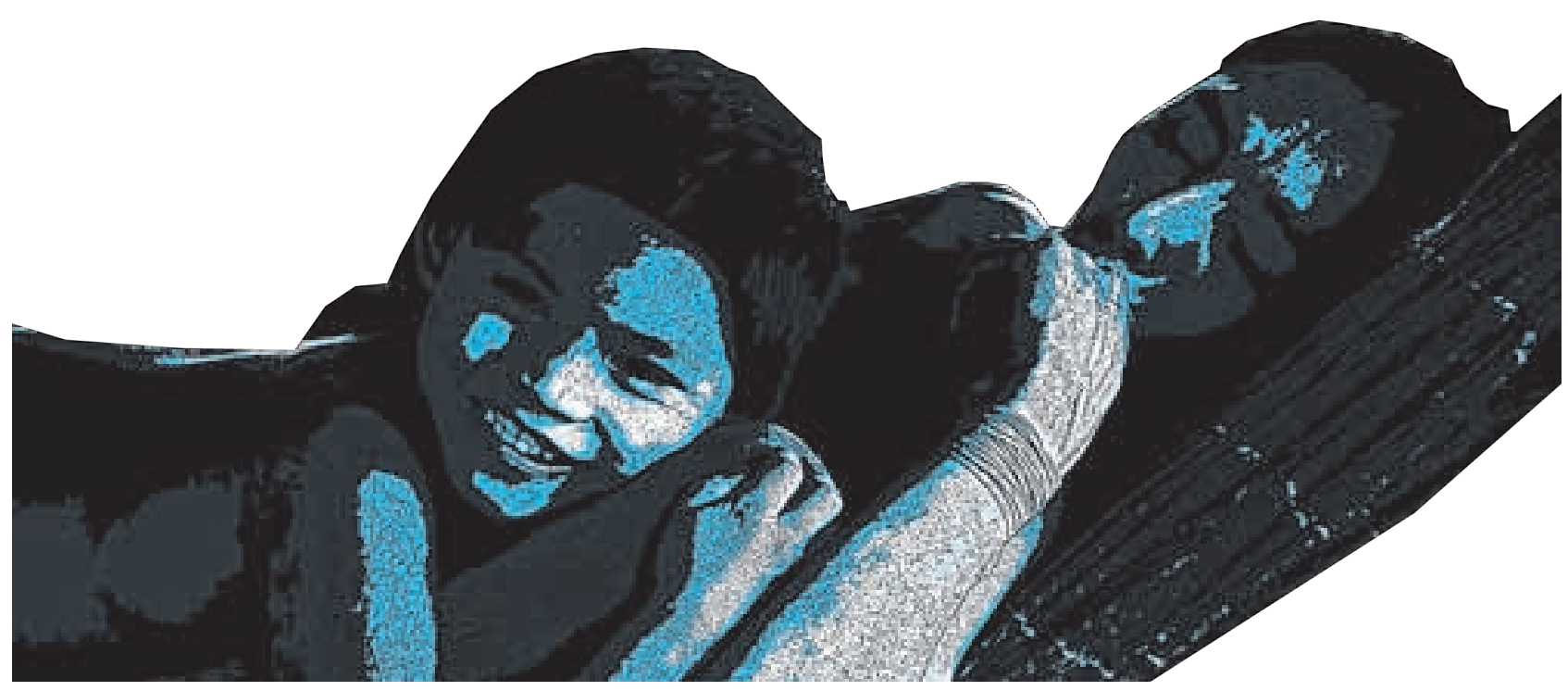




\section{Indigenismo e itinerancias territoriales}

El indigenismo es una corriente ideológica que analiza las causas de las desventajas históricas que los pueblos indígenas han estado afrontando, sobre todo a partir de la invasión europea en América (Favre, 1998) . Como política se propone la tarea de incorporar de una manera organizada a las poblaciones indígenas dentro del imaginario moderno de la humanidad. Las considera desde una perspectiva histórica, con tendencia a descomponerse en la medida del avance de las sociedades mayoritarias hacia su desarrollo económico, y en la adquisición de poder político y de capital social y cultural (Aguirre Beltrán: 1991).

Si bien, como afirma una reciente publicación sobre Diversidad Étnica y Cultural de Guatemala: "El indigenismo es una política que el Estado en discurso ha dejado de utilizar" (SEPAZ, 2010), su ideología ha permanecido. Cuando hablo de ideología indigenista, me refiero a las desiguales relaciones entre no-indígenas con "lo indígena", desde el siglo XV. Relación que con la sobreviniente época conocida como "colonia", se tornó en persecución por parte de los invasores, y en sobrevivencia por parte de los pueblos americanos. Estas acciones subyacen a una serie de creencias, procesos y acciones que Luis Villoro, historiador de las ideas, llama "conciencia indigenista" (Villoro, 1996). Esta se ha alimentado de cosmovisión religiosa, racionalismo y cientismo, además de la contemporánea "preocupación" histórica y social por los problemas de la desigualdad. El indigenismo es según ViIloro, un "conjunto de concepciones teóricas y de procesos concienciales que, a lo largo de las épocas, han manifestado lo indígena" (Ibíd.: 14). La política indigenista es entonces, la aplicación del aparato ideológico que se fue conformando con la influencia del pensamiento europeo. Ha sido otra vía para la colonización.

Como política, el indigenismo ha venido siendo reelaborado, pero también determinado por el choque cotidiano de intereses de los grupos que se hacen al poder. Así, el indigenismo termina siendo una forma de intervención del estado, sin necesidad de intervenir. Una herramienta elaborada de manera ideológica, para una función aparente, que escapa de control en manos de sus ejecutores directos.
Ejemplo de esto es la forma de contratación en el Proyecto Educador Comunitario Indígena -PECl-. Si bien es implementado como respuesta inmediata ante el levantamiento neo-zapatista del año 1994, sigue siendo una solución coyuntural, tal como fueron en su tiempo las otras iniciativas de vinculación magisterial indígena. Si bien al $\mathrm{PECl}$, se ingresa en calidad de "becario", el rol asumido es el de docente. Y aunque la beca finalizaría al completar los estudios, se presentan casos de permanencia laboral por más de diez años. De esta manera se ha estado empleando una figura de fachada para atender de manera desventajosa la educación, manteniendo en precarias condiciones el servicio.

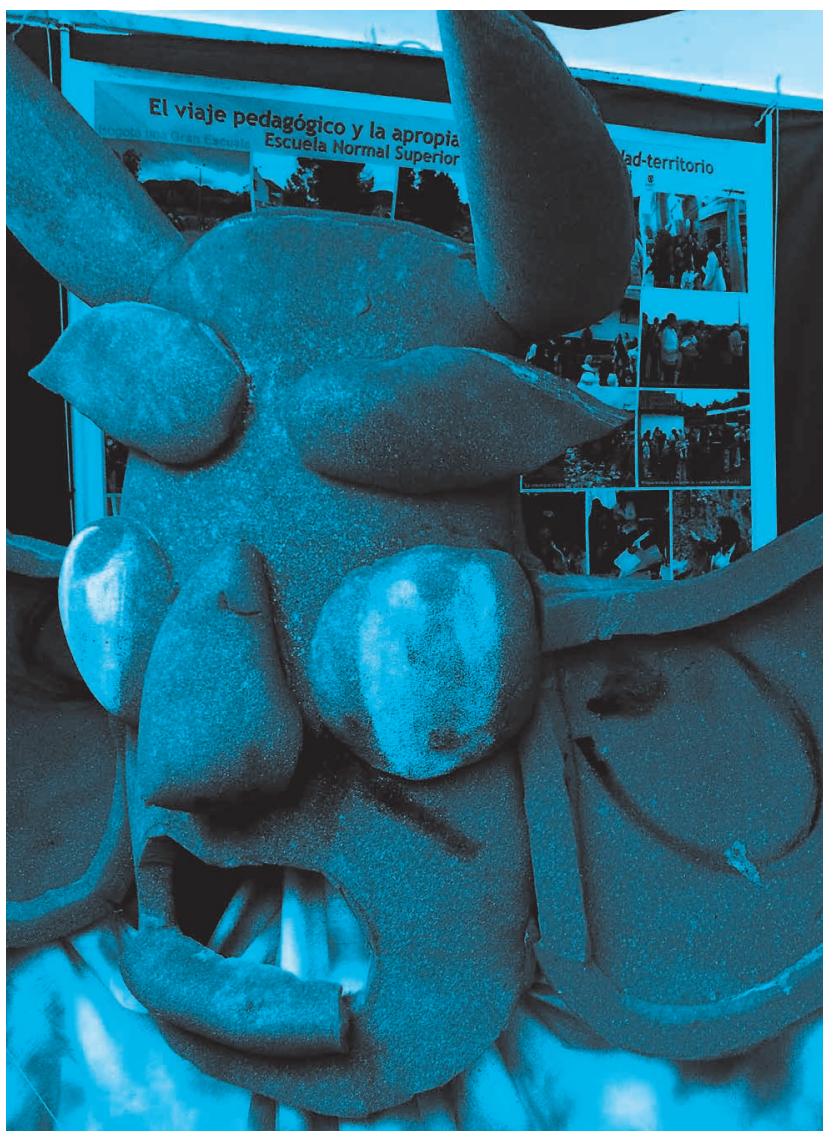


Similar situación sucedía en los años 1950 con los "promotores interculturales bilingües" (Aguirre, 1992, 1987). Pese a cumplir un rol docente, no se les nombraba en esa calidad. Fue así como una de sus demandas, era la de obtener su plaza en el magisterio, igual que la tenían los maestros federales -monolingües. El caso se replicó en territorio ch'ol durante la década de 1970. Allí iniciaban el trabajo en enfermería, cocina y promoción de la comunidad. Y con el tiempo y esfuerzos, lograron el nombramiento magisterial. Logros que se explican más por una formación cotidiana que ha obedecido a la sobrevivencia propia de los pueblos indígenas, que por las posibilidades ofrecidas en la política indigenista. La capacitación profesional, requisito que permitió el acceso a una plaza, fue conseguida con viajes largos y variados, de acuerdo a la tradición de desplazamientos ancestrales.

Es esto lo que identificamos como "Itinerancias territoriales". Una forma de estar en los territorios. Pero también uno de los modos de construir región, y de manera importante, una alternativa para las construcciones identitarias. Caminar por la región e intentar ir más lejos cada vez, ha sido una característica de los pueblos americanos (Morales, 1999). Testimonio de ello son los análisis arqueológicos sobre el norte de Chiapas. Según estos, en tiempos previos a la invasión europea, la gente ch'ol, perteneciente al tronco lingüístico maya, habitaba extensiones de terreno amplias. En una publicación del año 1994, auspiciada por el entonces INI, se afirma a este respecto que:

"Los ch'oles no siempre residieron en las comunidades donde viven actualmente. A lo largo de los siglos, después de que fueron arrancados de la selva, cambiaron sus zonas de asentamiento, huyendo del control de las encomiendas y tratando siempre de liberarse de la tutela de las haciendas que se multiplicaron en el estado de Chiapas a partir del siglo XIX. Su historia es también de resistencia, y lo expresaron al tratar de proteger lo que consideraban sus modelos de identidad" (Marion, 1994.: 88).

No extraña que en conversaciones con ch'oles actuales, se refieran a su presencia ancestral en territorios del hoy país de Guatemala. Sus recorridos por vastas extensiones de terreno permitió a la gente ch'ol formarse como caminantes de territorios. $Y$ es precisamente este "modelo de identidad" el que ha sostenido mi interés de búsqueda.
Contando con estas referencias sobre la no ubicación histórica ch'ol en un pedazo limitado de terreno, me di a la tarea de indagar en sus acciones cotidianas, la costumbre de caminar, pasear, desplazarse. Acudí a los desplazamientos cotidianos, pero también a los movimientos regionales en busca de tierras, trabajo, aprendizaje de la lengua castellana y demás motivaciones para andar. Fue así como a lo largo de 18 meses, caminando por Tila, visitando y haciendo estancias de algunos días y semanas en las comunidades, construimos conjuntamente con quienes decidieron ayudar, el territorio para esta investigación.

\section{El planteamiento inicial de investigación}

Pero mis intereses iniciales con respecto al trabajo de investigación estaban centrados en las dimensiones económicas de las etnicidades indígenas (Panqueba, 2011a, 2005a). Es decir, la búsqueda de los elementos que desde los intercambios, el mercado, la fuerza laboral y las alternativas de ingresos monetarios, constituyeran formas "propias" de construcción identitaria en el plano productivo (Ramírez, 2006; Coello et. Al., sf). Pero también me interesaba el tema educativo, pues en Colombia me desempeño como profesor de educación básica en una institución oficial cuya población beneficiaria es indígena (Panqueba, 2011; 2005b; 2004). Pensé entonces en la mejor manera de integrar aquellos intereses y la posibilidad de realizar una investigación que implicara el tema de las etnicidades, la escuela indígena y la educación.

De manera paralela, las lecturas de diferentes trabajos antropológicos aportaron otras bases que conocía de manera incoherente (Gamio, 2006; De la Peña, 2002, 1996). Llamó mi atención la forma como la república mexicana se convirtió en un laboratorio de las ciencias sociales, a partir de diferentes investigaciones aplicadas por reconocidos académicos (Molina Henríquez, 1985). La antropología aplicada fue entonces un foco sobre el cual centré mi atención. Y en ese marco, me dediqué a estudiar el indigenismo, su ideología y las políticas aplicadas en México desde mediados del siglo XX (Sáenz, 2007; Saldívar, 2008; Sanchez, 1999; Villoro, 1996; Warman et. Al., 1970).

Al plantear la investigación, buscaba superar un análisis sobre el empleo del aparato estatal, como medio de ejercicio político, económico y de poder (Pineda, 1993). 
Entonces propuse dos líneas a reconocer. Por un lado, los procesos de las acciones indigenistas en el ámbito educativo. Por otro, la construcción de etnicidades en su dimensión económica.

Propuse una pregunta de investigación relacionada con las trayectorias de vida magisterial, inicialmente teniendo en cuenta las experiencias de maestros veteranos. La atención se centraría en los elementos que hacían evidentes las negociaciones de etnicidades que, en su práctica, promueven giros al indigenismo y dinamizan la dimensión económica de las etnicidades (Flores Crespo, 2007).

\section{El trabajo de campo}

Iniciamos indagando en las experiencias de los maestros y las maestras con status de jubilación, las maneras en que habían ejercido su profesión al margen de las políticas que estaban siendo aplicadas en sus territorios. Políticas de las cuales ellos y ellas eran sus principales agentes. Habían recibido una formación para "castellanizar", "modernizar" y "sacar del atraso" a sus comunidades. Personalmente quería saber cómo había sido vivida aquella misión oficial. Algunos trabajos realizados sobre la educación indígena, daban cierta cuenta de este aspecto (Vargas, 1994; Pineda, 1993; Pérez Vásquez, 2007; Panqueba y Huérfano, 2006). Pero poco hacían referencia al cómo han sido transmitidos otros saberes, mucho más cercanos a los intereses de sus beneficiarios.

Durante la experiencia de establecer los contactos con maestros jubilados, fui dando cuenta de otros grupos magisteriales en ejercicio de sus labores. Ellos y ellas contaban con el conocimiento de las condiciones educativas actuales. Así llegamos a establecer la presencia de tres generaciones magisteriales en la región.

La primera generación está conformada por quienes se iniciaron como promotores culturales bilingües en la década de 1970. Pero también por quienes entraron directamente como docentes de base, compartiendo algunas particularidades de vida y labor con los primeros. Incluye a quienes ingresaron al servicio hasta mediados de los años 1980. Sus relatos los identifiqué como "testimonios de vida de itinerancias". Ello en virtud de su vasta experiencia en haber caminado diferentes regiones, antes de su vinculación magisterial.
La segunda generación ingresa al servicio desde mediados de la década de 1980 hasta finales del año 1998. Incluye también a quienes iniciaron cubriendo interinatos temporales y que lograron obtener una plaza definitiva, después de superar un proceso de selección basado en un examen escrito. Se les identifica regionalmente como los maestros "mochila veloz", dada su cotidiana movilización entre los apartados centros de trabajo y sus localidades de residencia.

Y la tercera generación está conformada por quienes se vinculan desde inicios de 1999 hasta el tiempo presente. Quienes colaboraron en esta investigación pertenecen en su mayoría al PECI. Su drama es conseguir una plaza base. Muchas son las postulaciones, pero pocas las plazas disponibles. Incluso se habla de agentes que coordinan los concursos y en ocasiones se rumora que alguien vende las preguntas de los exámenes. Quienes viven esta situación, cubren temporalmente plazas vacantes de docentes con incapacidad médica, licencia de maternidad o permiso para ocupar algún cargo político. Varias personas se han dedicado por años al cubrimiento de interinatos. Por sus características, esta generación es la de "maestros y maestras temporales".

Por otra parte, gracias a la interacción con las generaciones magisteriales, pero también con personajes no necesariamente vinculados a la educación, establecimos tres dimensiones-dinámicas de la vida regional. Una de peregrinación sagrada en torno al cristo negro de Tila. Otra como región prestadora de servicios educativos, gracias entre otras a las gestiones de los y las maestras ch'oles para dinamizar su profesión. Y una tercera como región proveedora de mano de obra, caracterizada en los últimos años por el creciente número de jóvenes en disposición de migrar hacia el norte de la república mexicana, para insertarse en la oferta laboral agrícola.

La primera dimensión-dinámica brindó información sobre las actividades cotidianas y económicas en torno a la iglesia San Mateo de Tila y al cerro de la cruz. Escenarios del culto al cristo de Tila, que hace parte del circuito mesoamericano de cristos negros junto al de Esquipulas en Guatemala, Otatitlán y Chalma en México (Ramírez Shadow, 2002; Velasco Toro, 2002; Navarrete, 1999; Josserand, 2007, 1996). La peregrinación regional ha diversificado no sólo las manifestaciones de fe sino también de cotidianidades económicas. Este auge asociado 
a la veneración de la imagen del señor de Tila se ubica aproximadamente a finales de los años setentas (Josserand, 2007). La coincidencia con la caída de los precios para la venta de café y el crecimiento del casco urbano tileco, dieron origen a las diferentes formas de comercio en torno a las peregrinaciones ordinarias, así como a las celebraciones religiosas. Entre estas el 15 de enero, día del señor de Tila; la fiesta de la cruz en mayo, la semana santa, la fiesta del Corpus Cristhi y el día de la virgen de Guadalupe entre otras fechas del calendario católico.

La dimensión-dinámica de la región como prestadora de servicios educativos es evidente por la presencia de instituciones educativas desde preescolar, hasta preparatoria. Hubo también un momento entre los años 1997 y 2002 en que funcionó el proyecto Ch'ol, a través del cual obtuvo su titulación de licenciatura en educación, un buen número de la actual población magisterial. El programa fue una oportunidad para el gremio y para la juventud interesada en formarse profesionalmente. La promoción de Tila como centro poblacional capaz de albergar la educación superior fue innovadora. Si bien los maestros proyectaron su pueblo como prestador de un servicio educativo en el nivel profesional, también desnudaron un problema: La sobre-oferta magisterial.

Entre las iniciativas precedentes de creación de centros educativos con servicios complementarios, escuelas y albergues, fue importante el trabajo de los maestros rurales. Impartiendo clases a la sombra o el abrigo de frondosos árboles (Dirección General de Culturas Populares, 1987), se dieron a la tarea de gestionar ante los gobiernos, y de motivar y coordinar con las comunidades sus escuelas. Luis, maestro de la generación primera nos compartió la manera cómo gestionó la legalización de su escuela. Si bien venía funcionando previamente sin el reconocimiento de la Supervisión educativa, Luis la erigió como un lugar digno de sus estudiantes y de su trabajo. La comunidad era su jefa. Puso su experiencia de itinerancia en la adecuación del espacio, realizó alfabetización de adultos y la dinamizó con actividades deportivas y artísticas. De esa manera buscó el estatus legal con aval de la Supervisión de Educación. Ello sin embargo le representó ponerse a disposición del citado ente, viendo cómo su paso firme de cinco años, termina en forma lacónica.

Por último, la dimensión-dinámica de la región como proveedora de mano de obra ofrece una larga historia de movimientos migratorios en busca no sólo de solventar la situación económica. Por ejemplo, en los testimonios de la primera generación magisterial, es recurrente el interés por conocer, caminar en otras regiones, e incluso conseguir un mejor manejo de la lengua castellana. En el actual mercado laboral de la región se distinguen tres posibilidades. En primer lugar, los trabajos campesinos: rozar, cortar café, tumbar monte, cortar y acarrear leña, limpiar milpas y cafetales (Alejos, 1994, 1999, 2002, 2004). En segundo lugar, la mano de obra para una población en su tránsito a convertirse en 'ciudad rural'. En tercer lugar, tenemos la docencia como posibilidad. Pero también como instancia ante las dificultades para desempeñar otra profesión. El cuadro laboral quedaría incompleto sin tener en cuenta la asignación 'natural' de funciones según género y edad. Ello se observa en la dinámica del improvisado mercado desde tempranas horas de la mañana. Al sitio llegan señoras y señores de diferentes colonias a vender yuca, plátano, posol, chayotes, café, cebollas y algunas variedades de frutas. Otras señoras residentes en la cabecera municipal venden comidas rápidas y caseras como empanadas, cucuruchos, tacos, café, posol y pan.

Quienes no tienen la opción de participar del comercio u otras actividades diferentes a la ocupación agrícola, salen a buscar empleos en territorios ya andados por sus antepasados. Sus ocupaciones van desde las rurales en ranchos ganaderos y cultivos de plátano en Campeche y Tabasco, hasta los empleos como ayudantes de albañilería en ciudades como Villahermosa (Tabasco) y Cancún (Quintana Roo). También se ocupan en servicios de aseo en construcciones o trabajos de vigilancia con empresas radicadas en las playas de Cancún (Quintana Roo) y Playa del Carmen. Las mujeres se colocan como vendedoras y personal de limpieza en los comercios. También son preferidas como empleadas del servicio doméstico en las ciudades. Otro grueso de población tiene su destino al norte de la república mexicana como "trabajadores del campo".

Por su correspondiente descripción, cada una de estas dimensiones-dinámicas ha aportado elementos para la construcción de una identificación muy fuerte con el tránsito regional e interregional. $Y$ en consecuencia, la construcción de una vasta experiencia de itinerancias territoriales muy ligadas a las estrategias que el mercado, el comercio y el emprendimiento, han aportado a la formación de varias generaciones de hombres y mujeres 
ch'oles. A través de este seguimiento pudimos ir determinando cuatro jubilaciones del indigenismo.

Jubilaciones del indigenismo

\section{Jubilación primera: ¡Si jubilarse fuera llenarse de júbilo!}

Una primera jubilación es que la oferta magisterial crece en medio de un servicio educativo prestado en condiciones precarias y en medio de la falta de mayores oportunidades laborales, económicas y de bienestar para la región (Así puede deducirse de los datos del Conteo 2005 sobre niveles de escolaridad).

Una manifestación de esta jubilación primera tiene que ver con las expectativas que despierta el desempeño laboral, profesional, ocupacional o temporal en el magisterio. La docencia es vista como un paso intermedio entre la prepa y la formación profesional en áreas que verdaderamente gusta a la juventud. El testimonio de una joven maestra en una comunidad, así lo confirma:

"Ser maestra no me llamaba la atención antes, mi sueño era ir a estudiar pero no pude salir. Quería yo estudiar medicina, ese era mi sueño. Pero no tenemos lo suficiente para ir a estudiar en otro lado, por eso es que yo no salí (...) A pesar que no me llamaba la atención [ser maestra], me metí por la necesidad que tiene uno. Por la necesidad de seguir estudiando, tener un trabajito y seguir estudiando pues". (Patricia, agosto 15 de 2008).

Otra es la situación cuando alguien que ya ha estudiado una licenciatura en un campo ajeno a la docencia debe acudir a vincularse al gremio magisterial, esta vez en educación secundaria. Al parecer el camino hacia el desempeño y desarrollo profesional tiene cortapisas y la manera de asumirlas es vinculándose a la docencia como ejercicio temporal desde donde puedan catapultarse los desempeños acordes a la formación profesional y a las expectativas de vida personal. El testimonio de un maestro ch'ol que se encuentra vinculado a un Cobach así lo describe:

"Sinceramente mi vocación no es trabajar frente a grupo, yo siempre me propuse esa meta de tener una carrera pero no en el nivel en que estoy ahorita, no en el área; yo soy ingeniero agrónomo. Pero yo siempre quise estudiar lo que es lenguas, eso me gustó a mí. Pero todavía no me doy por vencido, posiblemente lo estudie; con el trabajito que ya tengo ahorita posiblemente estudio todavía. (...) Claro que mi carrera pues igual me perfila en muchas cosas, no sólo en el ámbito de lo que es trabajar en la escuela. También puedo trabajar con proyectos productivos, llámese agropecuarios, apícolas, lo que es forestal. Sinceramente la carrera que yo tengo es amplio; abarca varios sistemas, pero te digo, voy a estudiar otra carrera todavía (...)" (Santiago, agosto 23 de 2008).

Los dos testimonios dan cuenta de cómo los y las jóvenes de la tercera generación magisterial han tenido que asumir la escasez de oportunidades para vincularse a campos de acción acordes con sus gustos. La docencia, luego de significar regionalmente un punto de llegada para generaciones anteriores, hoy representa un punto en el camino hacia la satisfacción de otras expectativas. La docencia ha significado un puerto estabilidad momentánea. Ello mientras se logran cubrir profesionalmente otros campos que usualmente han ocupado personas que llegan desde lugares ajenos a la región. Una situación que queda planteada, pero que no alcanza a cubrir el presente trabajo, es el tema de la movilidad social generacional. Es decir, las experiencias de diversificación profesional a las que mayoritariamente han tenido acceso los hijos y las hijas de docentes.

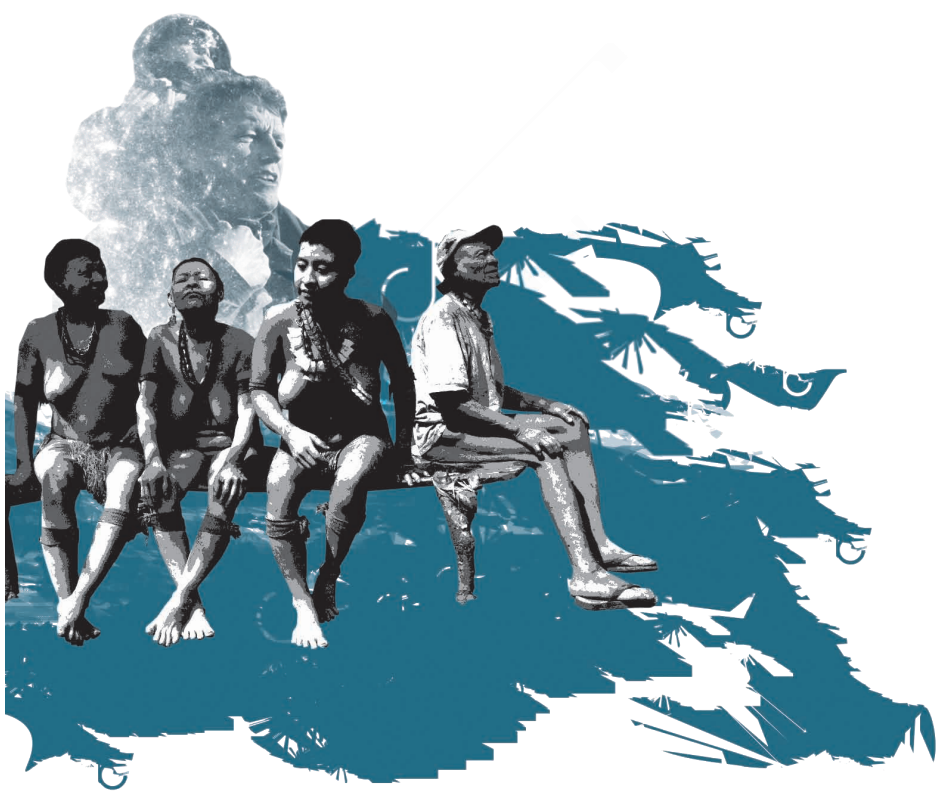


Jubilación segunda: emular otras itinerancias en un contexto cada vez menos itinerante

Una segunda jubilación del indigenismo, es la sucedida sobre la otrora concepción que la labor docente tenía en las comunidades educativas. La itinerancia territorial ch'ol ha permitido que la juventud de la región tenga claro que uno de sus destinos es buscar alternativas laborales y de ingresos económicos en lugares distantes. Entre la población ch'ol, el paso al territorio norteamericano es una posibilidad cada vez más sólida. En esta ampliación de los destinos y de la relativa diversificación de ocupaciones, las itinerancias van siendo re-creadas y re-producidas.

Estas últimas situaciones evocan la misión de los maestros veteranos y su apostolado en torno a preparar sus estudiantes en la idea de salir, recorrer, echarse andar. Al margen del trabajo indigenista, fueron llevando a cabo otras acciones que educaron tanto a estudiantes como a la población en general para la cual ellos eran el ejemplo a seguir. No bastó que estos "agentes" del indigenismo, estuvieran sometidos bajo un aparato de dominación política a través del cual se pretendió la transmisión de "valores modernos" por medio de la educación.

Trabajar, caminar y aprehender por otros territorios alejados del municipio han sido necesidades para varias generaciones ch'oles. Pero la formación en la itinerancia opera de una manera paradójica en el ámbito local. En muchos casos relacionados con la dimensión económica de las etnicidades, los maestros de la primera generación pasan de la itinerancia, a jugar un papel mucho más relacionado con el emprendimiento de negocios en la cabecera municipal. Pasos que siguieron hombres y mujeres de la segunda generación magisterial, relegando a un segundo plano su oficio docente. Ello a riesgo de afectar su asistencia a los centros de trabajo y por ende, la calidad de los procesos académicos y de aprehendizaje. El apelativo 'mochila veloz' es la descripción resumida de los hechos en que han incurrido.

Para el magisterio de la tercera generación, sus maestros pasaron de ser ejemplos de itinerancia como posibilidad en manos de la gente ch'ol, a ejemplos de emprendimiento mercantil. Es un cambio observado en la movilidad social fincada en la participación política y en la vida del

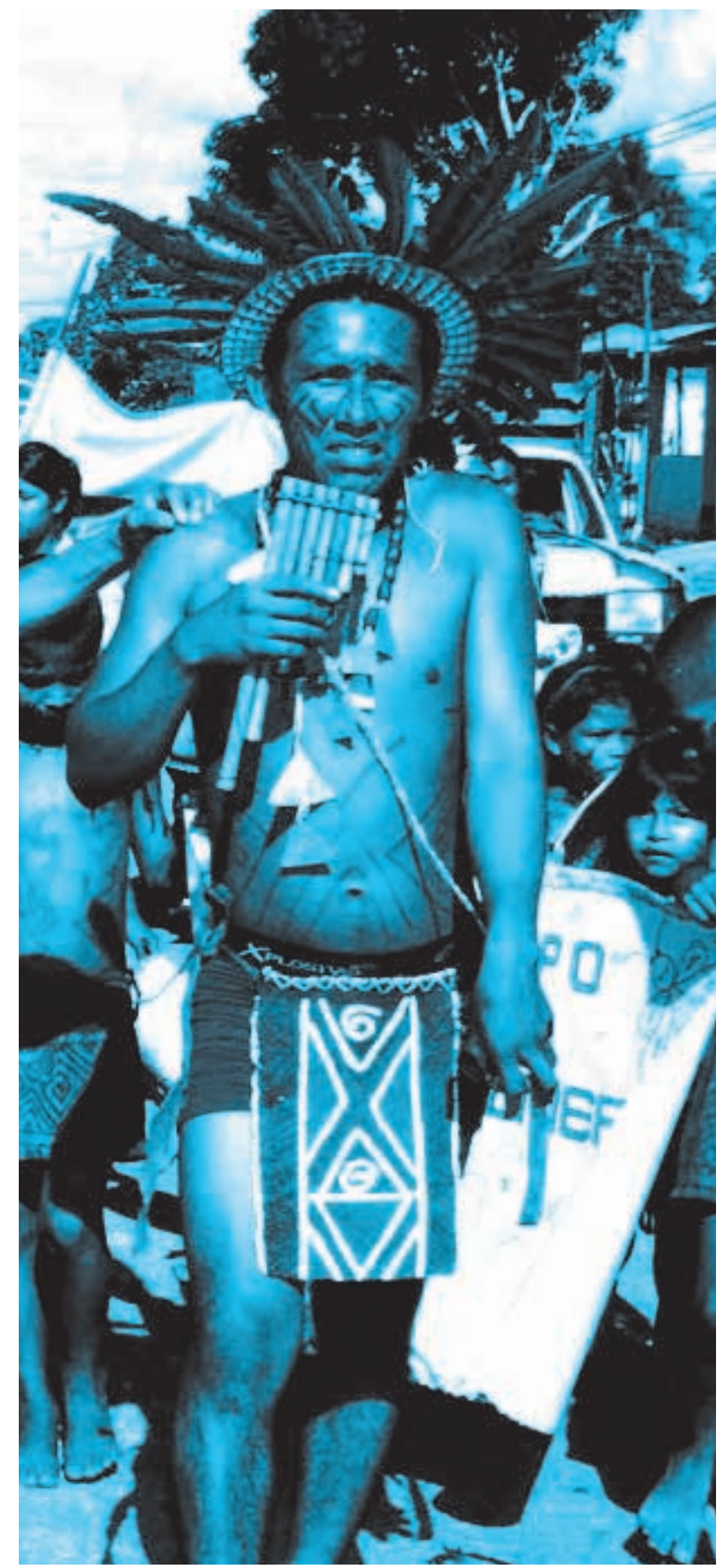


mercado regional, más que por el hecho mismo del ser educadores.

Ahora, por encima de émulos en los esfuerzos personales, familiares y comunitarios para conseguir el acceso a educación que no estaba presente en la región, "Ios maistros" vienen destacando como prototipos de emprendimiento no precisamente en el ámbito pedagógico. Las habilidades para el comercio han venido siendo un modelo que se fortalece como característica a emular por quienes recién entran a la docencia.

En este contexto de producción y re-producción comercial, se suceden tímidas propuestas creativas y re-creativas que mantienen de alguna forma el estatus de las itinerancias como parte de la etnicidad. Esto en oposición a la creciente itinerancia laboral que profundiza los estereotipos étnicos. Hay casos de comprometidos maestros que buscan formarse en nuevas tecnologías, o que se vinculan a programas de post-grado. Otros maestros han contribuido con investigaciones sobre el idioma ch'ol, produciendo algunos materiales bibliográficos y didácticos para el sistema de educación indígena.

\section{Jubilación tercera. La invisibilización del trabajo femenino en la construcción de la dimensión-dinámica proveedora de mano de obra.}

Una tercera jubilación del indigenismo puede encontrarse en los censos. Allí la participación de las mujeres como población económicamente activa (PEA) es muy parcialmente tomada en cuenta. Aunque en todos los datos se diferencian las ocupaciones por sexo, el trabajo femenino continúa oculto, a juzgar por la realidad que se aprecia en las comunidades.

Si bien los hombres, en compañía de sus hijos cuidan de la milpa y realizan trabajos pesados como cargar leña, tumbar, rozar y quemar monte para preparar los terrenos, recolectar hierbas medicinales, entre otras actividades, las mujeres también lo hacen. Solo que su trabajo se considera en términos de "ayuda", esta es una de las razones por las que en los censos se les ha relegado. Por ejemplo, el corte de café es una labor que requiere de muchas manos; niñas, niños y mujeres trabajan a la par de los hombres en los cafetales. Los números tampoco tienen en cuenta el trabajo femenino, ni siquiera cuando los hombres emigran a trabajar a otros territorios.

Con la emigración mayoritariamente masculina, a los oficios como el proceso del maíz, el fríjol y el café, regularmente llevados a cabo por las mujeres, se suman los tradicionalmente ejecutados por los hombres. Pero aún con la presencia masculina, los trabajos femeninos son fundamentales para la producción agrícola. Sin la mano trabajadora de las mujeres, serían toneladas de café perdidas en cuestión de un día. Su labor ha sido fundamental para el sostenimiento económico de las familias que sacan algunos kilos de café desde las montañas chiapanecas.

De la misma forma como son invisibilizados los trabajos femeninos, sucede con los infantiles. Desde muy tempranas horas de la madrugada, los caminos, la vía pavimentada y los senderos son recorridos por hombres, mujeres, jóvenes, niñas y niños, llevando los implementos necesarios para el trabajo en sus milpas y cafetales. Quienes van a las escuelas, llevan también un cuaderno y un lápiz entreverados en su mochila.

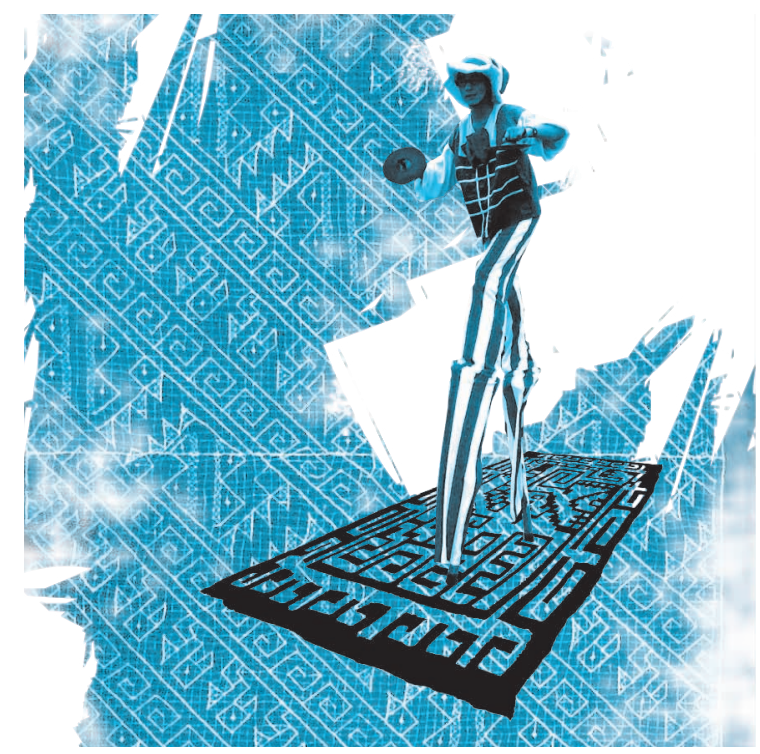




\section{Cuarta jubilación del indigenismo: el poder del estado en manos del magisterio bilingüe}

Y la cuarta jubilación del indigenismo que quiero presentar se refiere al poder que el magisterio indígena maneja con relación a la manipulación de las etnicidades. Ello porque una vez que alguien cuenta con una plaza docente, entra en un universo un poco más amplio de posibilidades de desempeño. El salario fijo y la estabilidad laboral fungen como garantías para que una persona pueda aventurarse a jugar en escenarios que, históricamente han estado vetados -simbólica y materialmente- para la incursión de indígenas. Sobre el particular encontramos un caso en que se emplea la figura del neo-zapatismo para acceder a ciertas prebendas.

La situación obedece a la identificación como 'zapatista' o 'autónomo' frente a los 'hermanos ch'oleros' ${ }^{\circ}$ frente a otras personas y grupos. Sucede que son varios los maestros propietarios de taxis, quienes participan en el mercado del transporte local. De este mercado hacen parte los "taxistas autónomos" y los "taxistas legales". Y jugando con la figura regional de "la autonomía", muchos buscan redituar sus capitales a partir de las identidades comunes en la región ${ }^{2}$, bien sea buscando la evasión de un impuesto, un beneficio particular o la salvación de una obligación ante su ejido.

Es una forma de manifestación de poder en la cual el magisterio participante cuenta con los recursos económicos, ideológicos y simbólicos para actuar en medio del universalismo nacional y el particularismo étnico. De esta manera aprovechan la conciencia indigenista más viva que nunca en los territorios, en las personas y en las instituciones del Estado. Dicho esto, quiero concluir la presentación con unas reflexiones motivadas por las juiciosas lecturas realizadas a este trabajo.

\section{Para concluir: las entre luces indigenistas}

Agradezco la lectura crítica por parte de las personas del jurado aquí reunidas, porque gracias a ella he profundizado en mi hipótesis de considerar al indigenismo, una ideología en aparente decadencia. En este trabajo podemos encontrar una continuidad de la conciencia indigenista. El indigenismo no ha muerto, no ha desaparecido de las formas de educación en México, de las formas en que se presenta en la vida cotidiana de indígenas y no indígenas. El indigenismo se ha transformado; la conciencia que lo alentó permanece en los cuerpos de mexicanos y mexicanas. Persiste como un gen la idea de la inferioridad indígena, la cual sólo se convierte en lo contrario en la deslumbrada retórica de los movimientos new age, que han traspasado incluso las luchas históricas y hoy toman los supuestos valores espirituales, de maneras inocentes, lucrativas y también abusivas.

Al respecto, tal vez hubiera sido un poco más accesible hacer un trabajo de campo en cualquiera de las ciudades mexicanas que últimamente he frecuentado. Más difícil sin embargo, y de manera paradójica, ha sido hacerlo en los territorios de donde es originaria la población indígena que hoy tiene presencia en las ciudades. En las comunidades hay precariedad, en las ciudades también. Pero son precariedades distintas. En las comunidades se lucha por la invisibilización étnica de una manera más difícil que en las ciudades. Pero también se lucha para visibilizarse y hacerse a las relativas ventajas que hay reservadas para las personas indígenas (Hale, 2004).

Lo que afirmo es que, a pesar de las evidencias sobre la supuesta extinción del indigenismo, tales como los cambios en las formas de administrar, la delegación de gestiones en manos de autoridades comunitarias, la creación de para-autoridades con el fin de organizar de otra manera a las comunidades para el acceso a las políticas del Es-

\footnotetext{
1. Una manera muy común de referirse y/o dirigirse una persona a otra en la región es decirle 'hermano'. Esto refleja un nivel de reconocimiento del otro como coterráneo, colega, amigo, vecino o conocido. En el caso de esta investigación muy pocas veces escuché referirse o dirigirse una mujer a otra como 'hermana'. Pero si hay mujeres que en encuentros casuales en el camino pronuncian la palabra 'hermano' para dirigirse a un hombre, o de mujeres que se refieren a un hombre cuando están hablando de él.

2. Laboral: campesino, taxista, agricultor, tortillero (a), maestro, etc.; Partidaria: priista, perredista, panista, etc.; Ideológica: zapatista, autónomo, ch'olero; Por lugar de vivienda: de colonia, del pueblo, del campo, de la montaña, etc.
} 
tado, persiste de manera casi imperceptible su ideología. Si bien el indigenismo surge como una política dirigida a los pueblos indígenas, también estaba dirigida a toda la población nacional.

La ideología indigenista fue sembrando tanto en el imaginario de nación, como en las personas, la distinción entre "lo indígena" atrasado, anómalo y pre moderno, y "lo indígena" como lo exótico, lo esotérico y anclado en el ideal ancestral de lo que fueron las raíces de la nación mexicana. En esa medida, había que acabar con toda representación de un supuesto lastre para la modernidad. Y por otra parte, conservar en la memoria, en los museos y en la vida rural, los proclamados valores positivos que la ideología indigenista propagaba. Esta conciencia permanece. Por este motivo es importante la revisión de los discursos clásicos sobre los cuales se fue edificando tanto la política indigenista, como la conciencia que la incubó.

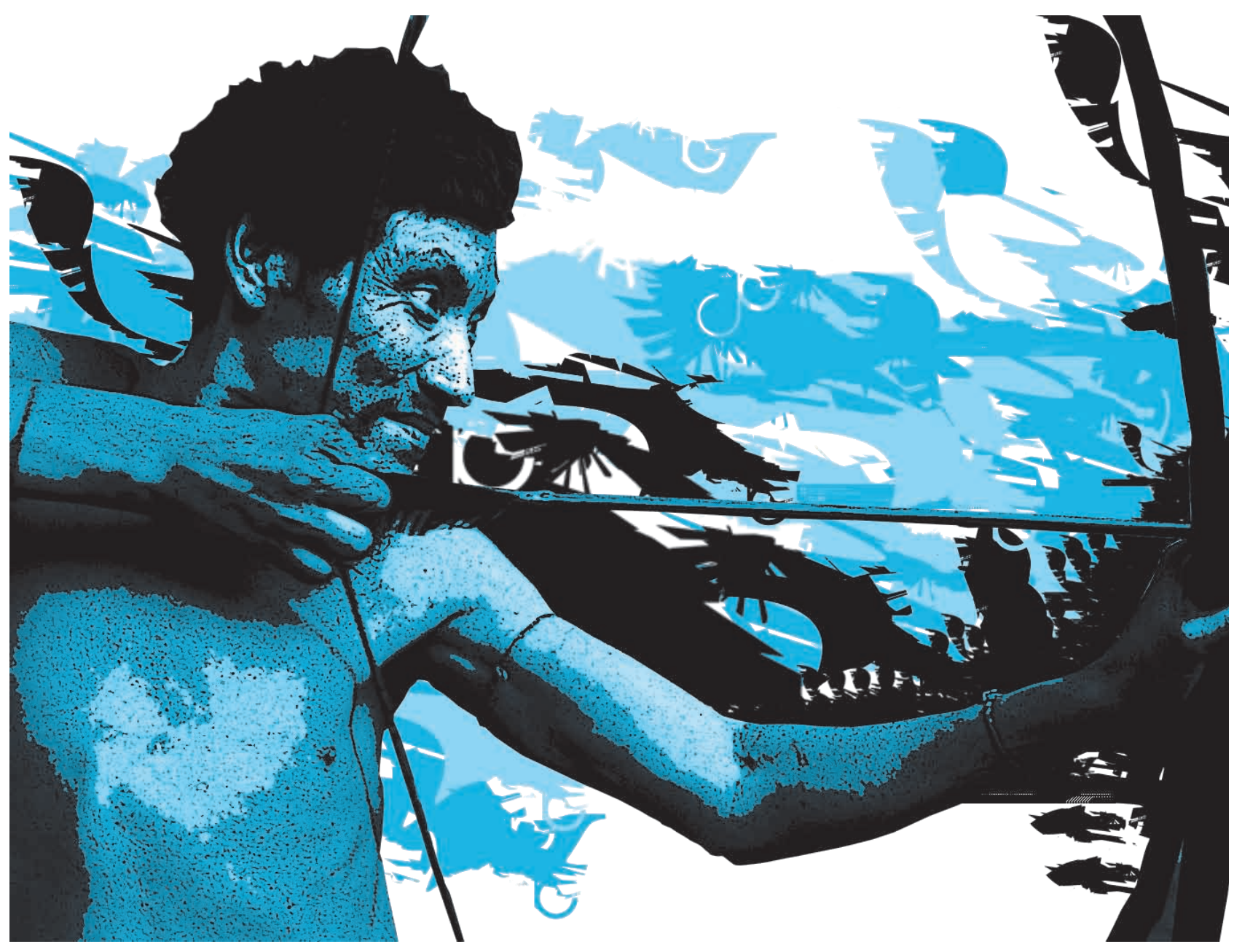




\section{Bibliografía}

Aguirre Beltrán, G. (Sf.). El indigenismo y la antropología comprometida. Folleto.

Aguirre Beltrán, G. (1992). [1957]. El proceso de aculturación. México: Fondo de Cultura Económica.

Aguirre Beltrán, G. (1991). [1953]. Formas de gobierno indígena. México: Fondo de Cultura Económica.

Aguirre Beltrán, G. (1987). [1967]. Regiones de refugio. El desarrollo de la comunidad y el proceso dominical en mestizoamérica. México: Instituto Nacional Indigenista.

Alejos García, J. (2004). "Identidad étnica y conflicto agrario en Chiapas". En: Amérique Latine Histoire et Mémoire, numéro 10-2004. Identités: positionnements des groupes indiens en Amérique latine. Disponible en: ( http://alhim.revues. org/document114.html) ó (http://www.pensamientocritico.org/josale1105.htm.), última actualización. Agosto 21 de 2007.

Alejos García, J. (2002). [1995]. Los choles en el siglo del café: estructura agraria y etnicidad en la cuenca del río Tulijá. Chiapas: Los rumbos de otra historia. En Juan Pedro Viqueira y Mario Humberto Ruz (edts.). pp. 319-330. México: UNAM/ CIESAS/ CEMCA/ Universidad de Guadalajara.

Alejos García, J. (1999). Ch'ol/Kaxlan. Identidades étnicas y conflicto agrario en el norte de Chiapas. $1914-1940$. México: UNAM.

Alejos García, J. (1994). Mosojäntel. Etnografía del discurso agrarista entre los ch'oles de Chiapas México: UNAM.

Coello, M.; Sara María L. y Humberto C. (Sf.). Capitalismo y campesinado indígena (Los choles de Chiapas). p. 66. México: Mimeo.

De La Peña, G. (2002). El futuro del indigenismo en México: Del mito del mestizaje a la fragmentación neoliberal. En Yamada Mutsuo y Carlos Iván Degregori (orgs.). Estados nacionales, etnicidad y democracia en América Latina. JCAS Symposium Series 15. pp. 45-64. The Japan Center for Area Studies (JCAS). Nacional Museum of Ethnology. Osaka, Japón.

De La Peña, G. (1986). "Poder local, poder regional: perspectivas socioantropológicas". En Jorge Padúa y Alain Vanneph (compds.). Poder local Poder Regional. pp. 27-56. México: El Colegio de México/ CEMCA.

Dirección General de Culturas Populares. (1987). Los maestros y la cultural nacional 1920- 1952. Volumen 5: sureste. Museo Nacional de Culturas Populares y Mëxico: Autor.

Favre, H. (1998). El indigenismo. México: Fondo de Cultura Económica.

Flores-Crespo, P. (2007). Ethnicity, identity and educational achievement in Mexico. In: International J ournal of Educational Development. Volume 27, issue 3, may. pp. 331-339. Elsevier Ltd. Available online at www.sciencedirect.com

Gamio, M. (2006). [1916]. Forjando patria. México: Editorial Porrua.

Hale, C. (2004). Rethinking indigenous politics in the era of the "indio permitido", NACLA Report on the Americas, 38 (2). September/ October 2004. 
Josserand, J. K. y Hopkins, N. A. (2007). "Tila y su Cristo Negro: historia, peregrinación y devoción en Chiapas, México". En Mesoamerica, revista del Centro de Investigaciones Regionales de Mesoamerica (CIRMA). Año 28, número 49, enero/ diciembre. Plumsock Mesoamerican Studies, ISSN 0252-9963.

Josserand, J. K. y Hopkins, N. A. (1996). Lenguaje Ritual Chol. Informe de investigación. Fundación para el Avance de los Estudios Mesoamericanos, Inc. Council for Faculty Research Support, Florida State University, National Endowment for the Humanities, y National Science Foundation. Disponible en: http://www.famsi.org/cgi-bin/print_friendly.pl?file=94017es. Julio 4 de 2007.

Marion, M. O. (1994). Fiestas de los pueblos indígenas. Identidad y ritualidad entre los maya., México: Secretaría de Desarrollo Social (SEDESOL) - Instituto Nacional Indigenista (INI).

Molina Henrríquez, A. [1909]. (1985). Los grandes problemas nacionales y otros textos. México: Editorial Era.

Morales Bermúdez, J. (1999). Antigua palabra. Narrativa indígena ch’ol. México: Plaza y Valdés, UNICACH.

Navarrete Cáceres, C. (1999). "El Cristo Negro de Esquipulas: origen y difusión. En: Estudios, agosto 1999, 3a época. Revista del Instituto de Investigaciones Antropológicas, Arqueológicas e Históricas, Escuela de Historia, C. de Guatemala. Universidad de San Carlos.

Panqueba Cifuentes, J. F. (2011ㄹ). "Indígenas del 'otro' lado de Bogotá, Colombia: Semblanza sobre sus memorias cotidianas e identificación histórica". En: Revista de Antropología Social DESACATOS, número 35, septiembre-diciembre. México: IESAS.

Panqueba Cifuentes, J. F. (2011b). (En prensa). "Elaboración y negociación de la pobreza indígena. Jugosas ganancias para el desarrollo capitalista en Ecuador y Colombia." En: Compilación sobre estudios comparados de la pobreza en América Latina. Buenos Aires: CLACSO.

Panqueba Cifuentes, J. F. (2005ạ). Política, pobreza e identidad étnica: Estudio comparado sobre la dimensión económica de las luchas indígenas en Colombia y Ecuador, con posteridad a los reconocimientos constitucionales de la diversidad étnica. Informe final de investigación realizada como becario junior del programa CLACSO-CROP de estudios sobre pobreza en América Latina y el Caribe (Convocatoria 2004- 2005). Argentina: Consejo Latinoamericano de Ciencias Sociales, CLACSO.

Panqueba Cifuentes, J. F. (2005b). El "otro" lado de Bogotá: memoria cotidiana e identificación histórica de la comunidad indígena muisca de Bosa. Tesis de maestría en Ciencias Sociales con mención en estudios étnicos. Quito: Facultad Latinoamericana de Ciencias Sociales, FLACSO.

Panqueba Cifuentes, J. F. (2004). "Danza glocal del "otro" lado de Bogotá: una experiencia de re-creación cultural desde ritmos andinos colombianos en la comunidad indígena muisca de Bosa". En Panqueba, Jairzinho y otros. Pensar la danza. Bogotá: Instituto Distrital de Cultura y Turismo (IDCT)-Alcaldía mayor de Bogotá.

Panqueba, J. et al. Huérfano A., et al. (2006). Experiencia reowayabtyba. Informe final de la investigación titulada: El "otro" lado de Bogotá: experiencia glocal de reconstrucción étnica en la comunidad indígena muisca de Bosa, desde sus memorias y cotidianidades. Bogotá, D.C.: Instituto Distrital para la Investigación y el Desarrollo 
Pedagógico, IDEP, Fundación Universitaria los Libertadores, Secretaría de Educación Distrital, Cabildo Muisca de Bosa, Colegio San Bernardino (Bosa).

Pérez Vásquez, R. (2007). Maestros bilingües: intermediarios y grupos de poder en la región norte de Chiapas. Tesis de Maestría en Antropología Social Guadalajara: CIESAS- Occidente.

Pérez Castro, A. B. (1989). Entre montañas y cafetales (Luchas agrarias en el norte de Chiapas). México: Universidad Nacional Autónoma de México.

Pineda, O. (1993). Caciques Culturales (El caso de los maestros bilingües en los Altos de Chiapas. Puebla, México. Altres Costa-ACIC.

Ramírez, A. (2006). Pueblos indígenas, Pobreza y Desarrollo Humano en México 1994- 2004. En Hall, Gillette y Harry Anthony Patrinos. (2006). Pueblos Indígenas, Pobreza y Desarrollo Humano en América Latina 1994-2004. Bogotá. Banco Mundial y Mayol Ediciones. (Publicado originalmente en inglés como: Indigenous Peoples, Poverty and Human Development in Latin América. (2006). World Bank).

Rodríguez-Shadow, M. J. et al. Shadow R. D. (2002). El pueblo del Señor: las fiestas y peregrinaciones de Chalma. México. Universidad Autónoma del Estado de México.

Sáenz, M. [1909]. (2007). México íntegro. México: Consejo Nacional para la Cultura y las Artes.

Saldivar, E. (2008). Prácticas cotidianas del Estado. Una etnografía del indigenismo. Universidad Iberoamericana. México: Editorial Plaza y Valdéz.

Sánchez, C. (1999). Los pueblos indígenas: del indigenismo a la autonomía. México: Siglo XXI editores.

Valdés Rodríguez, F. R. (1983). La peregrinación de los chontales: hermandad, control y poder. Tesis. México: UAM.

Vargas, M. E. (1994). Educación e ideología. Constitución de una categoría de intermediarios en la comunicación interétnica. El caso de los maestros bilingües tarascos (1964- 1982). México: Centro de Investigaciones y Estudios Superiores en Antropología Social (CIESAS)-Secretaría de Educación Pública.

Velasco Toro, J. (2000). De la historia al mito: mentalidad y culto en el Santuario de Otatitlán. Veracruz: Instituto Veracruzano de Cultura.

Villoro, L. (1996). [1950]. Los grandes momentos del indigenismo en México. $3^{a}$ Edición. México. Fondo de Cultura Económica, COLMEX y El Colegio Nacional.

Warman, A. et al. (1970). De eso que llaman antropología mexicana. México: Editorial Nuestro Tiempo. 